\title{
APRENDIZAGEM BASEADA EM DESAFIOS APLICADA EM CURSO DE ENGENHARIA DE COMPUTAÇÃO
}

Edilson Carlos Caritá - ecarita@unaerp.br

Universidade de Ribeirão Preto, Programa de Mestrado Profissional em Saúde e Educação Av. Costábile Romano, 2201 - Ribeirânia - Sala 18A

14096-900 - Ribeirão Preto - SP

Otávio Marson Junior-omjunior@unaerp.br

Universidade de Ribeirão Preto, Centro de Ciências Exatas, Naturais e Tecnologia

Av. Costábile Romano, 2201 - Ribeirânia - Sala 18 A

14096-900 - Ribeirão Preto - SP

Cristiane Rose Rossi Mazzoni - crismazzoni54@gmail.com

Universidade de Ribeirão Preto, Programa de Mestrado Profissional em Saúde e Educação Av. Costábile Romano, 2201 - Ribeirânia - Sala 18A

14096-900 - Ribeirão Preto - SP

Silvia Sidnéia da Silva - sssilva@ unaerp.br

Universidade de Ribeirão Preto, Programa de Mestrado Profissional em Saúde e Educação Av. Costábile Romano, 2201 - Ribeirânia - Bloco J

14096-900 - Ribeirão Preto - SP

Resumo: Hodiernamente, responsáveis pela condução de cursos de engenharia devem adotar metodologias de ensino-aprendizagem que contribuam ativamente para que os estudantes adquiram as habilidades e competências previstas nas diretrizes curriculares, bem como almejadas pelo mercado de trabalho. O objetivo desse estudo é apresentar o uso da metodologia da Aprendizagem Baseada em Desafios no processo ensino-aprendizagem de um curso de Engenharia de Computação de uma universidade privada do interior paulista. Tratase de estudo exploratório-descritivo, de caráter quantiqualitativo. $O$ estudo foi realizado no Curso de Engenharia de Computação de uma Instituição de Ensino Superior privada do interior paulista. Os dados foram coletados com o coordenador do curso e com uma amostra de 12 alunos finalistas das nove edições do Desafio. O coordenador do curso relatou a metodologia dos Desafios e os estudantes responderam sobre suas percepções ao participar das edições. Os resultados demonstraram que $100 \%$ dos alunos evidenciaram que o desafio contribui para a formação, permitindo aquisição de habilidades e competências; 92\% mencionaram que a participação no desafio foi motivada pela busca de novos conhecimentos e enfatizaram que oportunizou o aprendizado de novas tecnologias, falar em público, trabalhar em equipe, estimular a criatividade, empreender e conseguir estágio. Considerando-se as percepções dos participantes, pode-se ratificar que a Aprendizagem Baseada em Desafios coadjuva significativamente para a aquisição de competências necessárias aos engenheiros, principalmente, aquelas rotuladas como do século XXI: "colaboração, solução de problemas, iniciativa e empreendedorismo, criatividade e inovação, comunicação oral e escrita eficaz”.

Palavras-chave: Aprendizagem Baseada em Desafios. Ensino de Engenharia. Processo Ensino-aprendizagem. Competências. 


\section{INTRODUÇÃO}

Os modelos educacionais e as metodologias de ensino-aprendizagem estão sendo revisados e reestudados pelos diferentes atores, responsáveis por promover uma educação de qualidade e formar profissionais capacitados para o mercado de trabalho. Nessa direção, a Taxonomia de Bloom, as Rubricas e as Metodologias Ativas ganharam notoriedade nos últimos anos, principalmente, no contexto do ensino superior, pois evidencia-se, constantemente, que o modelo disciplinar centrado no professor e conteudista favorece a memorização de conceitos, não possibilitando ao educando reorganizar e repensar estratégias criticamente, inviabilizando, muitas vezes, que adquira as habilidades e competências preconizadas nas Diretrizes Curriculares Nacionais (DCN), e esperadas pelas empresas que contratarão os egressos dos cursos superiores de engenharia.

Contudo, o modelo de ensino tradicional ainda é soberano nas instituições de ensino no Brasil, inclusive de ensino superior, em geral, há aulas expositivas ministradas por professor especialista e os estudantes, na maioria da vezes, memorizam os conteúdos com o objetivo de reproduzi-los nos processos avaliativos a que são submetidos para conseguir aprovação nas disciplinas e, consequentemente, concluir o curso.

É imprescindível para um engenheiro ser capaz de pesquisar e questionar e que, sobretudo, tenha as competências de pensar de maneira crítica e reflexiva, resolver problemas, formular hipóteses e interferências, além de tomada de decisões que contribuam para o bem do homem e das nações; portanto, um estudante de engenharia não pode ser um sujeito passivo no seu processo ensino-aprendizagem, ou seja, um mero receptor de conteúdos.

Atualmente, faz-se necessário que os estudantes aprendam de forma permanente, que tenham a competência de "aprender a aprender" para enfrentar as oportunidades do mundo do trabalho, extremamente competitivas.

Nesse sentido, para apoiar processos ensino-aprendizagem que visam formar profissionais competentes no sentido stricto, há as metodologias ativas, e dentre elas, a Aprendizagem Baseada em Desafios, do inglês Challenge Based Learning (CBL). De acordo com o Portal Desafios da Educação (2017) esta foi desenvolvida, em 2008, a partir de uma estrutura de aprendizagem criada pela Apple ${ }^{\circledR}$ para identificar os princípios essenciais de design de um ambiente de aprendizagem do século XXI (Century Learning Environment), que tinha como objetivo diminuir a evasão escolar.

A CBL é uma Metodologia Ativa que tem como ponto central o desenvolvimento de habilidades e competências para os desafios do século XXI, sua aplicação fomenta os alunos a solucionarem problemas reais contemporâneos; estimulando-os a planejarem ações, compartilharem experiências e discutirem sobre contextos relevantes que podem ser solucionados por eles (NICHOLS; CATOR; TORRES, 2016; BINDER et al, 2017; MORESI et al., 2017).

O objetivo desse estudo é apresentar o uso da metodologia da Aprendizagem Baseada em Desafios no processo ensino-aprendizagem de um curso de Engenharia de Computação de uma universidade privada do interior paulista.

\section{APRENDIZAGEM BASEADA EM DESAFIOS}

De acordo com Cecy, Oliveira e Costa (2010), a metodologia ativa refere-se a um processo ensino-aprendizagem centrado no aluno, que deixa o papel de receptor passivo e assume o de ator principal de sua aprendizagem.

"As metodologias ativas se propõem em substituir a memorização e a simples

transferência de informações e de habilidades, pela construção do 
conhecimento a partir da vivência de situações reais ou simuladas da prática profissional, estimulando a capacidade de análise crítica e reflexiva e o aprender a aprender" (CECY; OLIVEIRA; COSTA, 2010, p. 16).

Há diferentes processos de ensino-aprendizagem considerados metodologias ativas, destacando-se a Problematização, mormente pelo Arco de Maguerez; a Aprendizagem Baseada em Problemas (ABP), traduzida do inglês Problem Based Learning (PBL); Estudos de Caso; a Aprendizagem Baseada em Projetos; a Aprendizagem Baseada em Desafios e a Gamificação.

Johnson et al. (2009) ressaltam que um dos grandes desafios no processo ensinoaprendizagem é proporcionar ao educando um aprendizado significativo e que tenha relevância em sua vida e, nesse contexto, o uso das metodologias ativas tem o objetivo de apoiar essa inspiração.

A CBL é uma abordagem multidisciplinar de ensino-aprendizagem, na qual os alunos usam a tecnologia cotidiana como uma das ferramentas para resolver problemas reais. Com foco no enfrentamento de desafios locais e globais, a estrutura permite que os envolvidos adquiram conhecimentos de várias áreas, desenvolvendo, assim, um processo de aprendizado multidisciplinar que será permanente ao longo da vida (NICHOLS; CATOR; TORRES, 2016).

Ainda pode ser empregada desde o ensino fundamental até o ensino superior e, fundamentalmente, parte de um tema abrangente sobre o qual serão levantadas questões essenciais e norteadoras, atividades e reflexões e divide-se em três fases: engajar, pesquisar e agir. Para cada questão básica determinada é associado um desafio que deverá ser transformado em uma ação prática pelos educandos. É necessário que o tema inicial permita ser aberto em diversas questões (PORTAL DESAFIOS DA EDUCAÇÃO, 2017). É considerada uma metodologia adaptável que pode ser integrada a outras metodologias e que permite personalização no seu uso (MORESI; BARBOSA; BRAGA FILHO, 2018).

Conforme Johnson et al. (2009), a Aprendizagem Baseada em Desafios foi elaborada a partir da prática de PBL, permitindo, assim, que os alunos aprendam com problemas do mundo real participando de atividades em equipes colaborativas. Portanto, a CBL exige que os alunos façam algo acontecer, sejam inovadores e criativos.

A CBL simula um ambiente de trabalho e se fundamenta em bases como entender as habilidades do século XXI (educadores, estudantes e comunidade), currículo aplicado, avaliação informativa, cultura de inovação, conexão social e emocional; além do acesso à tecnologia (SANTOS, 2016).

Ainda segundo Santos (2016), esta abordagem permite que o participante realize pesquisas, integre a prática com a teoria e compartilhe os benefícios com a comunidade por meio do uso da tecnologia.

A referida metodologia apresenta elevado potencial de aplicação em diversas áreas e poderá auxiliar no desenvolvimento de habilidades voltadas à aprendizagem do futuro.

\section{METODOLOGIA}

Trata-se de um estudo exploratório-descritivo, de caráter quantiqualitativo.

O estudo foi realizado em uma Instituição de Ensino Superior privada do interior paulista, que conta com aproximadamente 8.000 estudantes, distribuídos em 21 bacharelados e 02 licenciaturas presenciais, nas três grandes áreas do saber: saúde, exatas e humanas, totalizando 23 cursos de graduação. Em nível de pós-graduação, são cinco programas stricto sensu em nível de mestrado e quatro de doutorado, além de programa de residência médica em dez áreas, cursos de especialização lato sensu e um colégio tecnológico. Na área de Engenharia a IES oferta os 
cursos de Engenharia Civil, Engenharia de Computação, Engenharia de Produção, Engenharia de Software e Engenharia Química.

O estudo foi desenvolvido junto ao Curso de Engenharia de Computação, que iniciou sua primeira turma em 2001, tem duração de 5 anos, ocorre no período matutino, a carga horária de é de 3.862 horas, e possui, atualmente, 138 alunos matriculados.

A coleta de dados ocorreu no período de maio a junho de 2020, por meio de entrevista com o coordenador do curso, com os membros do Núcleo Docente Estruturantes (NDE) do Curso recorrendo ao grupo focal mediado por tecnologia e com uma amostra de 20 alunos finalistas e membros de equipes que desenvolveram bons projetos nos nove Desafios que ocorreram no período de quatro anos e seis meses. Os estudantes responderam a um questionário encaminhado por e-mail, com quatro perguntas: três objetivas e uma discursiva, sendo: "participar do desafio contribuiu para a minha formação?"; "participar do desafio apoiou a aquisição de habilidades e competências?"; "participar do desafio me motivou a buscar novos conhecimentos?"; "o que motivou sua participação no desafio e quais as contribuições do mesmo para sua formação acadêmica e profissional?".

A análise quantitativa dos dados ocorreu por estatística descritiva com o uso do software Excel 2016 da empresa Microsoft Corporation, em que os resultados são apresentados em frequência absoluta e relativa.

A análise dos dados qualitativos se deu mediante análise de conteúdo utilizando-se da metodologia descrita por Freire (1990).

\section{RESULTADOS E DISCUSSÃO}

De acordo com o coordenador do curso estudado, os desafios são realizados semestralmente e contemplam como problematização temas contemporâneos pertinentes a projetos que egressos do curso de Engenharia de Computação deverão desenvolver, já tendo sido temas dos desafios: "Tecnologia da Informação para Segurança de Motociclistas"; "Cidades Inteligentes e Sustentáveis: transportes e saúde pública"; "Cidades Inteligentes e Sustentáveis: auxílio a portadores de deficiência ou solução de problemas urbanos"; "Domótica: tecnologia para gestão de recursos habitacionais"; "Desenvolvimento de objetos de aprendizagem"; "Gerenciamento do consumo de água"; "Games auxiliando nos programas de reciclagem"; "Games divulgando cidades inteligentes" e "Robôdente: computação aplicada a educação em saúde bucal infantil".

Os alunos recebem no início de cada semestre o briefing sobre o desafio que poderão participar, considerando que não é obrigatório, porém, os estudantes que participam recebem um ponto adicional nas disciplinas que estão cursando no semestre. A justificativa do coordenador do curso quanto a não obrigatoriedade deve-se à manutenção da qualidade dos projetos e a criatividade e inovação, pois no modelo proposto, só participam do Desafio os alunos que estão interessados e se dedicarão para vencer a competição.

Na Figura 1 apresenta-se um exemplo do briefing que os alunos recebem; há o objetivo do Desafio, a regra para composição da equipe, exemplos de aplicações e as datas das entregas.

A avaliação dos protótipos desenvolvidos se dá por meio de uma banca formada por docentes do referido curso e empresários da área de tecnologia da informação e/ou automação que são convidados para participarem das apresentações no final de cada semestre.

Os alunos que desenvolvem os dois melhores trabalhos indicados pela banca avaliadora são condecorados com uma medalha de mérito; e comumente, os empresários que participam das apresentações oferecem vagas de estágio ou até contratação àqueles que se destacam nos Desafios. 
Os docentes das disciplinas específicas do curso motivam, orientam e auxiliam os alunos na execução dos projetos, e sugerem novas temáticas para os próximos Desafios.

Nas Figuras 2 (tema "SmartCity"), 3 (tema "Desenvolvimento de Objetos de Aprendizagem") e 4 (tema "Games auxiliando nos Programas de Reciclagem") são apresentados os resultados dos protótipos desenvolvidos pelos participantes em algumas edições dos Desafios.

Os membros do NDE ressaltaram a importância do desafio para a formação dos alunos do Curso de Engenharia de Computação, pois trata-se de uma atividade baseada em metodologia ativa que favorece o aprender a aprender e a aprendizagem autônoma. Destacaram que no Desafio são disponibilizados problemas reais que privilegiam a criatividade, a inovação, o raciocínio lógico e a integração das disciplinas, o que maximiza a aquisição das habilidades e/ou competências inerentes ao engenheiro de computação.

Figura 1 - Exemplo do briefing de um Desafio

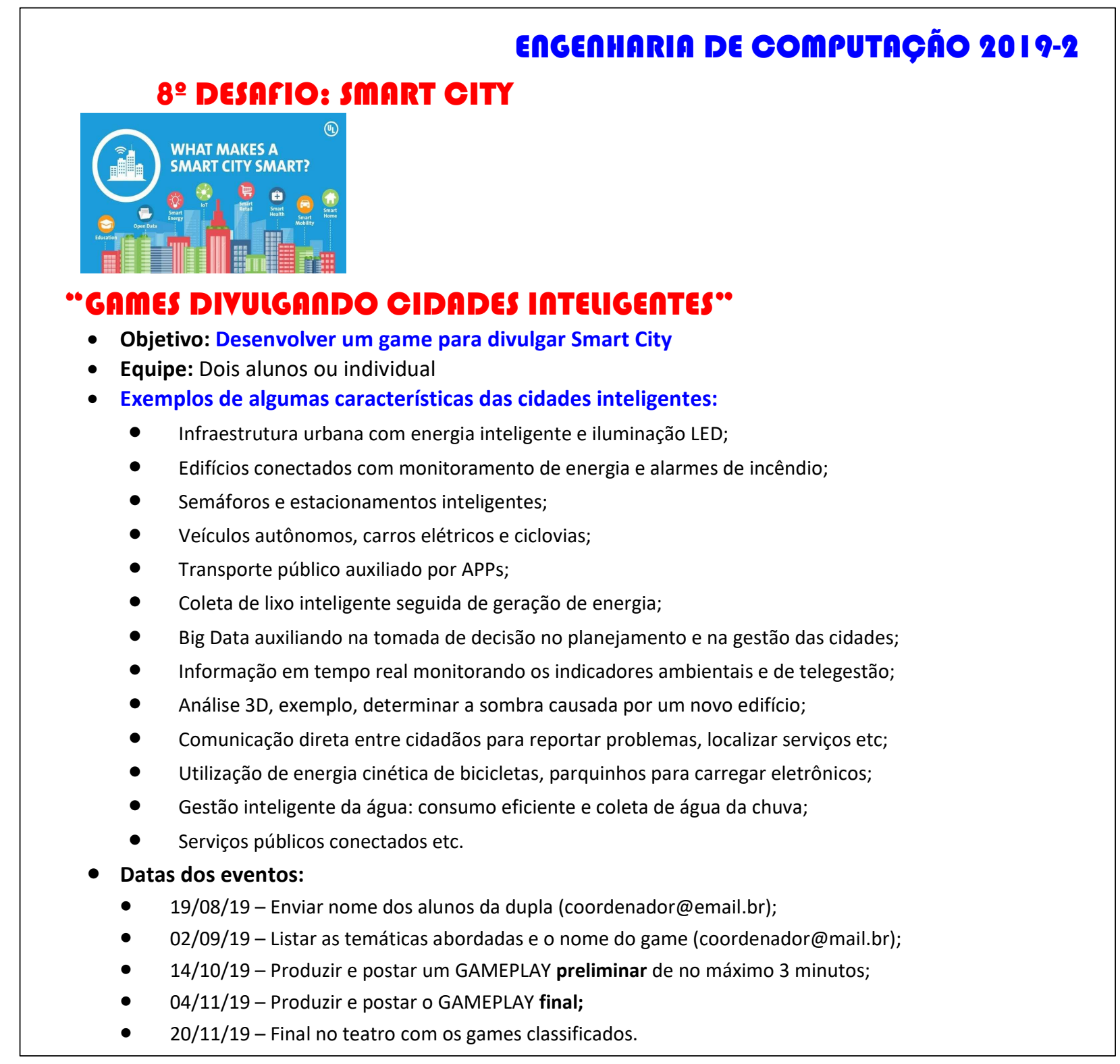

Fonte: Autoria Própria 


\section{COBENGE de Educação em Engenharia 2020 de Educaçäo}

"Os desafios para formar hoje o engenheiro do amanhã"

Figura 2 - Interface do software denominado Rotas Inteligentes, finalista do Desafio - tema "SmartCity"

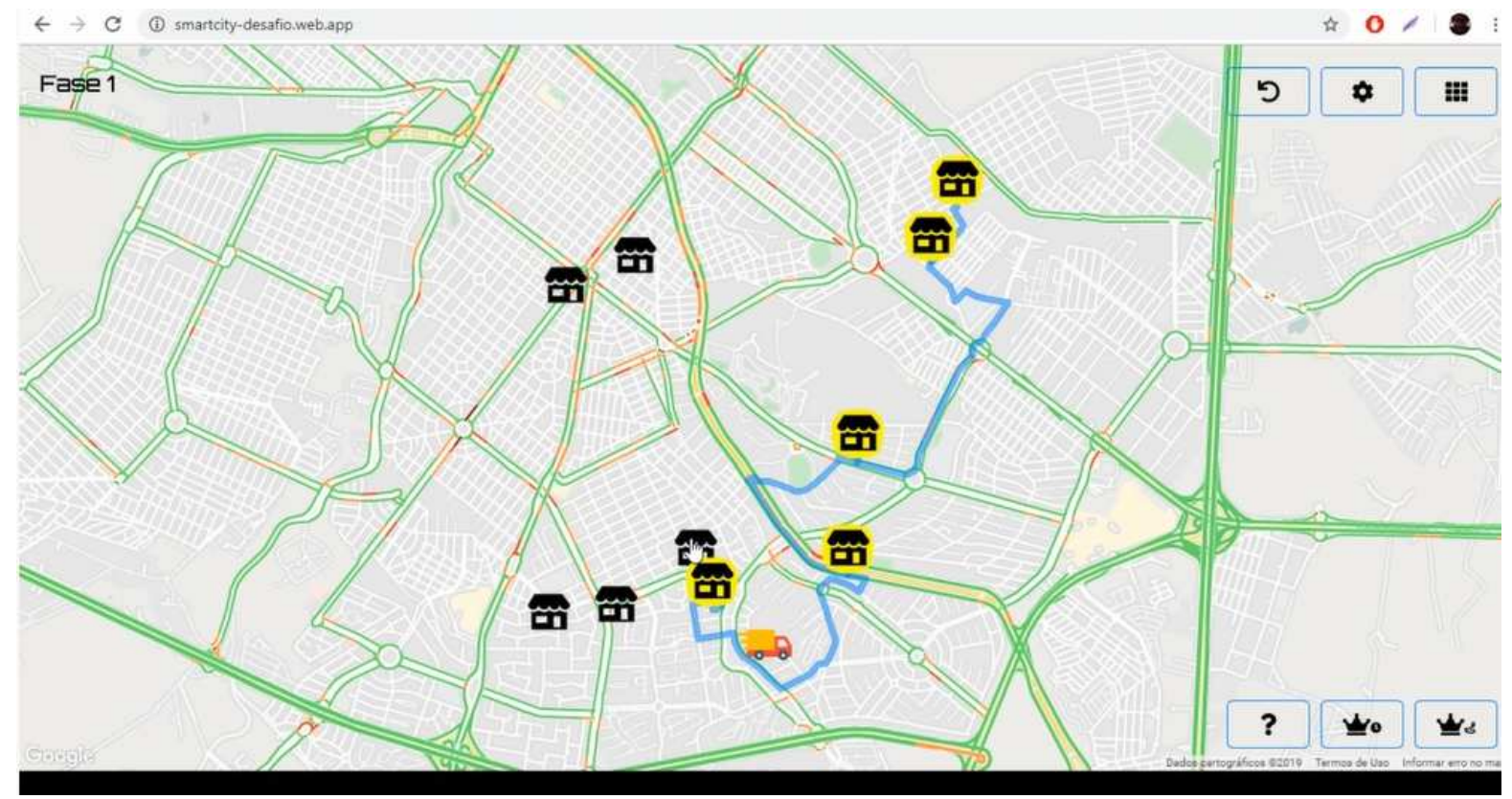

Fonte: Autoria Própria

Figura 3 - Interface do software Lab Histograma finalista do Desafio - tema "Desenvolvimento de Objetos de

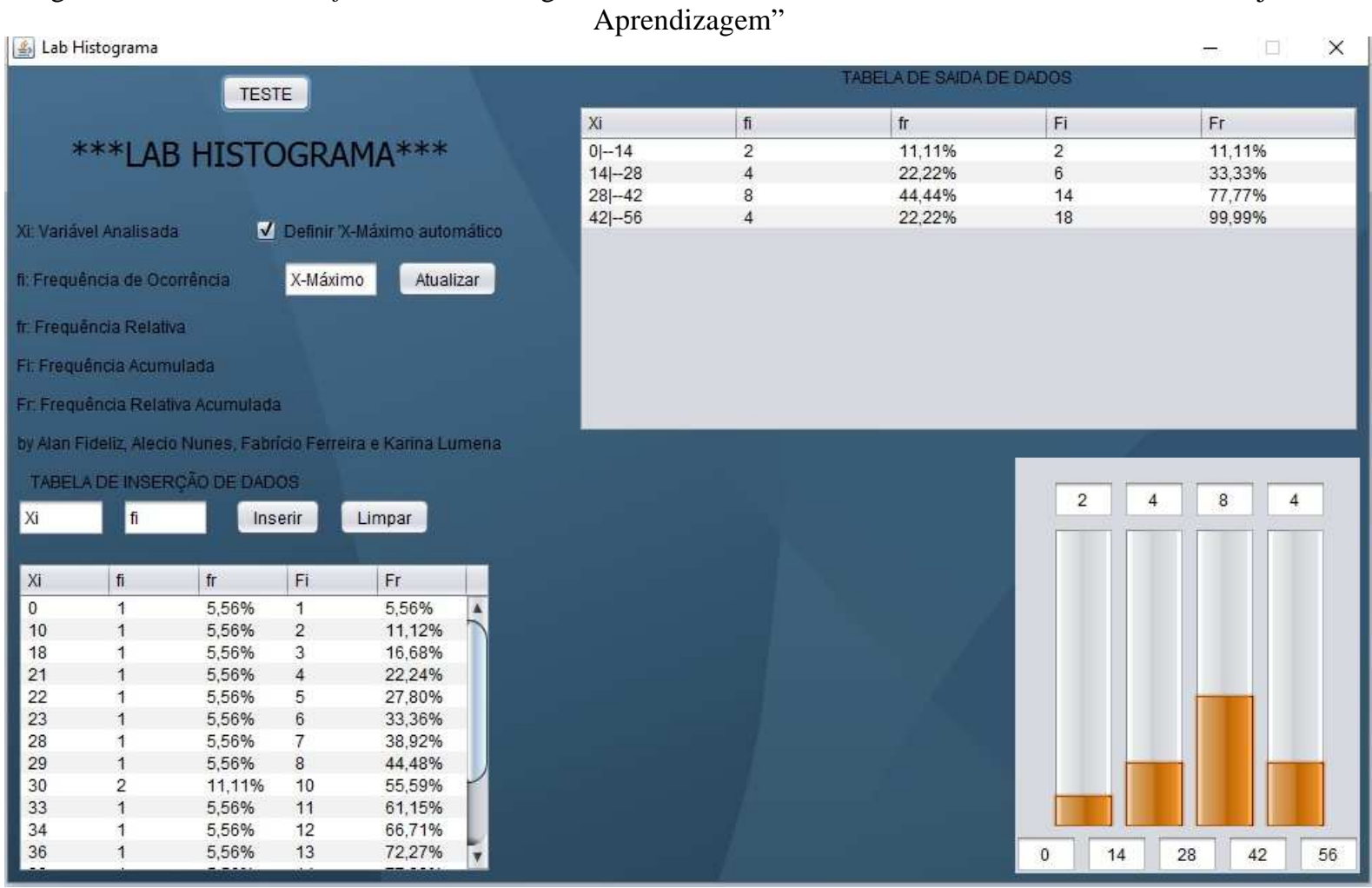

Fonte: Autoria Própria 


\section{COBENGE e III Simpósio Internacional de Educação em Engenharia da ABENGE}

"Os desafios para formar hoje o engenheiro do amanhã"

Figura 4 - Game finalista do Desafio tema "Games Auxiliando nos Programas de Reciclagem"

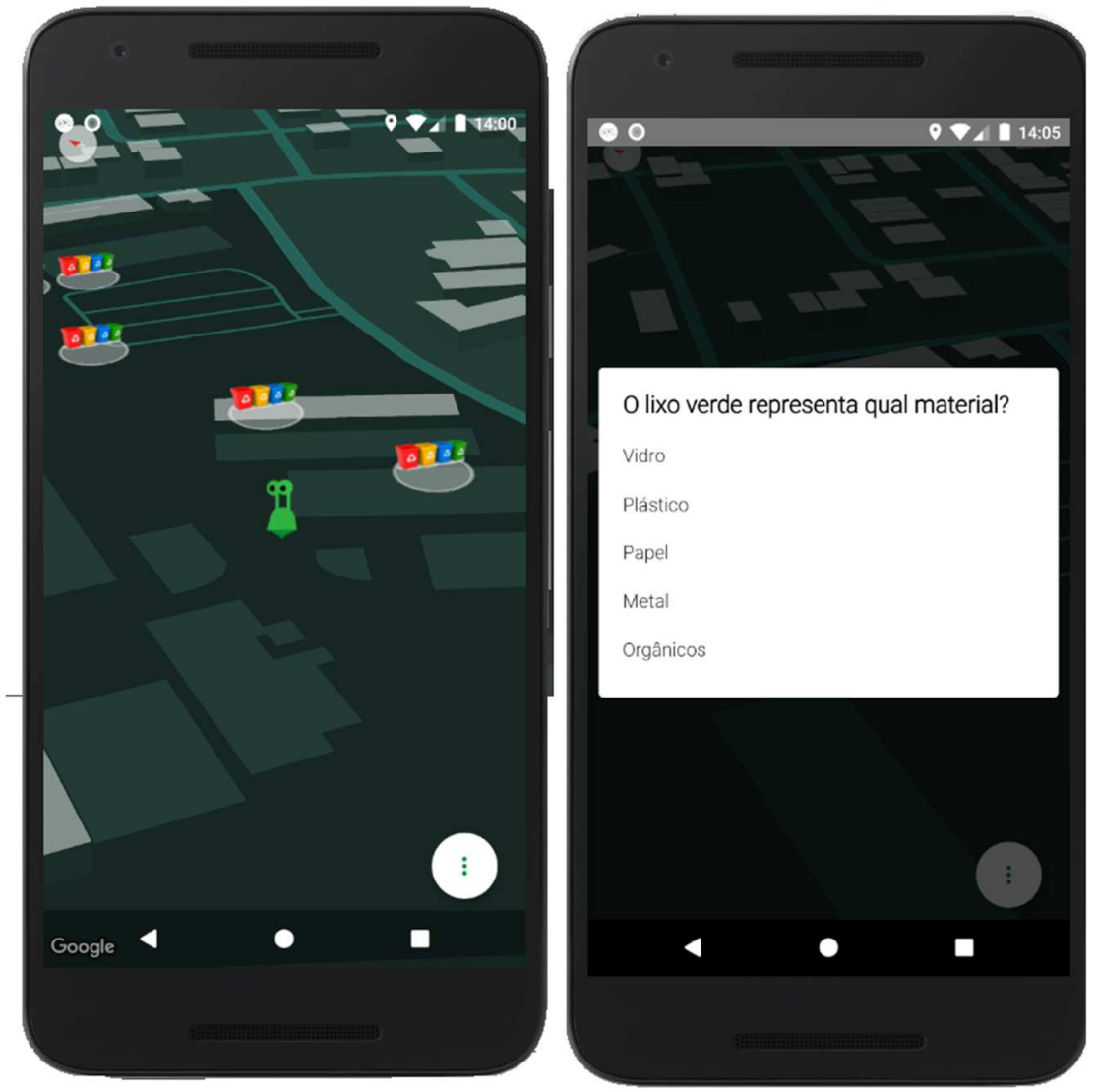

Fonte: Autoria Própria

Os resultados da análise dos dados coletados com os alunos finalistas e de equipes que desenvolveram bons projetos nas nove edições dos Desafios por meio do questionário demonstraram que 20 (100\%) deles evidenciaram que o desafio contribui para sua formação; todos (20 estudantes) afirmaram que este permite a aquisição de habilidades e competências; e $18(90 \%)$ mencionaram que a participação no desafio foi motivada pela busca por novos conhecimentos.

Para a análise qualitativa utilizou-se a metodologia descrita por Freire (1990), sendo que, após a leitura dos apontamentos escritos pelos participantes na questão "o que motivou sua participação no desafio e quais as contribuições do mesmo para sua formação acadêmica e profissional?", foram feitas as categorizações das respostas e, posteriormente, o agrupamento em temas geradores.

As principais categorias encontradas foram: aprendizado de novas tecnologias e conhecimentos extra curriculares, observada em 7 citações, como por exemplo: "Criação $e$ desenvolvimento de produtos, iniciando seu desenvolvimento a partir da aplicação para o mercado e experiência do usuário. Aprender novas tecnologias foi, também, um grande propulsor para minhas participações (desenvolvimento iOS e web)" e "Além do ponto extra nas disciplinas, foi também os conhecimentos extras que adquirimos, aplicações em problemas reais, ir atrás do conhecimento e trabalho extracurricular"; solução de problemas reais e mercado de trabalho, encontrada em 6 citações, como: "O desafio me proporcionou um pouco da forma que o mercado de trabalho funciona, tendo um período de tempo para resolver um problema que provavelmente será necessário aprender alguma ferramenta ou uma forma de realizar algo que talvez não exista, ou seja, precisei pensar de uma forma mais ampla para 
conseguir concluir o projeto da forma que havia planejado" e "...Como os desafios visam resolver problemas da vida real, faz com que os participantes pensam em como resolver o problema como um todo e não apenas em softwares e nas tecnologias".

Outras contribuições relatadas pelos participantes foram aquisição de novas habilidades e competências, perder o medo de falar em público, trabalhar em equipe, estimular a criatividade, empreender e conseguir estágio.

Contribuindo com achados do presente estudo, Johnson e Adams (2011 apud SANTOS, 2016) realizaram uma pesquisa com o uso da CBL e observaram aumento no comprometimento dos estudantes e no tempo que eles dedicaram para trabalhar nos desafios. Este estudo também identificou que a tecnologia foi usada de modo criativo e houve maior satisfação dos estudantes e melhora do aprendizado, da liderança, colaboração, flexibilidade, criatividade, e na resolução de problemas.

Moresi, Barbosa e Braga Filho (2018) utilizaram a CBL para definição e fundamentação de temas de pesquisa, e concluíram que ela pode orientar a pesquisa e o processo de revisão de literatura, permitindo um aprofundamento do aprendizado por meio do levantamento de informações fundamentais sobre o tema que será investigado.

Ainda corroborando, o estudo de Santana e Meira (2020), realizado em um curso de Direito, obteve resultados semelhantes e concluiu que a aplicação da CBL possibilita a orientação no processo de investigação e na construção de dados bibliográficos qualificados.

Aquino (2018) demonstrou em sua pesquisa que o uso da CBL para treinamento de potenciais empreendedores universitários pode facilitar o desenvolvimento de competências quando comparado com o treinamento tradicional, pontuando que foi identificado desenvolvimento superior em todas as habilidades investigadas.

\section{CONSIDERAÇÕES FINAIS}

O uso de metodologias ativas favorece o aprendizado do aluno ao incentivá-lo a participar do processo ensino-aprendizagem, de forma autônoma e ativa, responsabilizando-se pela construção de conhecimentos, aqui traduzidos na resolução dos problemas apresentados.

$\mathrm{Na}$ perspectiva do coordenador do curso, o Desafio, tornou-se uma ferramenta relevante no processo ensino-aprendizagem, pois contribui na efetivação de competências essenciais ao engenheiro, permite que a comunidade externa conheça o perfil dos alunos do curso, e proporciona estágios ou contratações a eles.

Considerando-se as percepções dos participantes, pode-se evidenciar que a Aprendizagem Baseada em Desafios coadjuva significativamente para a aquisição de competências necessárias aos engenheiros, principalmente, aquelas rotuladas como do século XXI: "colaboração, solução de problemas, liderança por influência, pensamento crítico, agilidade e adaptabilidade, iniciativa e empreendedorismo, criatividade e inovação, comunicação oral e escrita eficaz, flexibilidade, acesso e análise de informações e visão de negócios em inteligência artificial".

\section{REFERÊNCIAS}

AQUINO, L. M. P. de. Challenge based learning: uma análise do treinamento de competências profissionais em empreendedores. 2018. 70 f. Dissertação (Mestrado em Administração), Universidade Federal de Pernambuco., Recife, 2018.

BINDER, F. V. et al. Challenge Based Learning applied to Mobile Software Development 
Teaching. IEEE 30 ${ }^{\text {th }}$ Conference on Software Engineering Education and Training CSEE\&T, Savannah, Estados Unidos, 07 a 09 de novembro de 2017. Disponível em: $<$ https://ieeexplore.ieee.org/document/8166683>. Acesso em 26 jul. 2020.

CECY, C.; OLIVEIRA, G. A.; COSTA, E. M. M. B. Metodologias Ativas: aplicações e vivências em educação farmacêutica. Brasília: Associação Brasileira de Ensino Farmacêutico e Bioquímico, 2010.

FREIRE, P. Criando métodos de pesquisa alternativa: aprendendo a fazê-la melhor através da ação. In: BRANDÃO, C. R. Pesquisa participante. São Paulo: Brasiliense, 1990. p.34-37.

JOHNSON, L. F. et. al. Challenge-Based Learning: an approach for our time. Austin, Texas: The New Media Consortium, 2009. Disponível em: < http://rewiringeducation.com/wpcontent/uploads/2018/02/Challenge-Based_Learning-An_Approach_for_Our_Time.pdf >. Acesso em: 29 jun. 2020.

MORESI, E. A. D.; BARBOSA, J. A.; BRAGA FILHO, M. O. O emprego da metodologia Aprendizado Baseada em Desafios na elaboração da revisão de literatura. Atas do $7^{\circ}$

Congresso Ibero-americano em Investigação Qualitativa: Investigação Qualitativa na Educação, Aveiro, v. 1, n. 1, p. 69-78, jun. 2018. Disponível em:

<https://proceedings.ciaiq.org/index.php/ciaiq2018/article/view/1628>. Acesso em: 30 jun. 2020.

MORESI, E. A. D. et al. The use of challenge based learning in mobile application development. 12th Iberian Conference on Information Systems and Technologies (CISTI), Lisboa, Portugal, 21 a 24 de junho de 2017. Disponível em:

<https://ieeexplore.ieee.org/document/7975800/>. Acesso em: 26 jul. 2020.

NICHOLS, M.; CATOR, K.; TORRES, M. Challenge Based Learner: user guide. Redwood City, CA, 2016. Disponível em: < https://cbl.digitalpromise.org/wpcontent/uploads/sites/7/2016/10/CBL_Guide2016.pdf >. Acesso em: 30 jun. 2020.

PORTAL DESAFIOS DA EDUCAÇÃO. Aprendizagem Baseada em Desafios é chave para um ensino ativo. 2017. Disponível em:

$<$ https://desafiosdaeducacao.grupoa.com.br/aprendizagem-baseada-em-

desafios/\#: :text=Aprendizagem\%20Baseada\%20em\%20Desafios\%20\%C3\%A9\%20chave\% 20para\%20um\%20ensino\%20ativo,-

Por\%20Reda\%C3\%A7\%C3\%A3o\%2017\&text=Provocar\%20questionamentos\%20e\%20exer citar\%20a,do\%20ing1\%C3\%AAs\%20Challenge\%20Based\%20Learning).>. Acesso em: 29 jun. 2020.

SANTANA, H. L. de S.; MEIRA, L. A. A Aprendizagem Baseada em Desafios (ABD) como instrumento de qualitativo de pesquisa: o moot court como formato de Team Based Learning (TBL) no curso de Direito. Disponível em: <http://conpedi.danilolr.info>. Acesso em: 30 jun. 2020.

SANTOS, A. R. dos. Um Método de Aprendizagem Baseada em Desafios: um estudo de caso em ambientes de desenvolvimento de aplicativos. 2016. $179 \mathrm{f}$. Tese (Doutorado em 
Ciência da Computação), Pontifícia Universidade Católica do Rio Grande do Sul, Porto Alegre, 2016. Disponível em: < http://tede2.pucrs.br/tede2/handle/tede/7030 >. Acesso em: 29 jun. 2020.

\title{
CHALLENGE BASED LEARNING APPLIED TO COMPUTER ENGINEERING COURSE
}

\begin{abstract}
Abstract: At the present time, those responsible for conducting engineering courses must adopt teaching-learning methodologies that actively contribute for students to acquire the skills and competencies provided for in the curricular guidelines, as well as desired by the job market. The objective of this study is to present the use of Challenge Based Learning methodology in the teaching-learning process of a Computer Engineering course at a private university in the interior of São Paulo. This is an exploratory-descriptive study with a quantitative and qualitative nature. The study was carried out in the Computer Engineering Course of a private Higher Education Institution in the interior of São Paulo. Data were collected with the course coordinator and a sample of 12 finalist students from the nine editions of the Challenge. The course coordinator reported on the Challenges methodology and the students answered about their perceptions when participating in the editions. The results showed that $100 \%$ of students showed that the challenge contributes to training, allowing the acquisition of skills and competences; 92\% mentioned that participation in the challenge was motivated by the search for new knowledge and emphasized that it made it possible to learn new technologies, speak in public, work in teams, stimulate creativity, undertake and get an internship. Considering the participants' perceptions, it can be seen that Challenge Based Learning significantly contributes to the acquisition of skills needed by engineers, especially those labeled as 21 st century: "collaboration, problem solving, initiative and entrepreneurship, creativity and innovation, effective oral and written communication".
\end{abstract}

Keywords: Challenge Based Learning. Engineering Teaching. Teaching-learning process. Skills. 